\title{
LITERATURA, IMPRENSA E RESISTÊNCIA EM IDIOMA FRATERNO: PERCURSO DE UMA ESCRITORA VIAJANTE
}

\section{LITERATURE, PRESS AND RESISTANCE IN FRATERNAL IDIOM: JOURNEY OF A TRAVELLING WRITER}

\section{Elisabeth Batista*}

RESUMO: Maria Archer (1899-1982), escritora portuguesa, no período de 1955 a 1977, veio cumprir um largo exílio em terras brasileiras. Aqui, como nos territórios luso-africano, tornou-se um dos nomes de mulher mais importantes pela contribuição à imprensa de Língua Portuguesa. O nosso objetivo é trazer a reflexão pública sobre a contribuição da escritora para a resistência dos portugueses à ditadura do regime salazarista vigente em Portugal à época.

PALAVRAS-CHAVE: Maria Archer, exílio, imprensa, autoria feminina, salazarismo.

ABSTRACT: Maria Archer (1899-1982), a Portuguese writer, from 1955 to 1977, came to Brazil to live a long period of exile. Here, as in other Luso-African territories, she became one of the most important women due to her contribution to the press of Portuguese language. Our aim in this paper is to bring forward a public reflection about the contribution this writer gave for the resistance of the Portuguese people against Salazar's dictatorship in force in Portugal on that time.

KEY WORDS: Maria Archer, exile, press, feminine authorship, Salazarism.

\footnotetext{
* Mestre e Doutora em Estudos Comparados de Literaturas de Língua Portuguesa pela FFLCH-USP. Professora na UNEMAT - Universidade do Estado de Mato Grosso. Departamento de Letras - Campus Universitário de Cáceres. Emails: lisbatys@uol.com.br; lisbatys@terra.com.br.
} 



\section{LITERATURA, IMPRENSA E RESISTÊNCIA EM IDIOMA FRATERNO: PERCURSO DE UMA ESCRITORA VIAJANTE}

Navegadores antigos tinham uma frase gloriosa:

"Navegar é preciso; viver não é preciso"

Quero para mim o espírito dessa frase, transformada a forma para a casar com o que sou; viver não é necessário,

O que é necessário é criar.

De meados de 1955 a abril de 1979 a escritora e jornalista Maria Emília Archer Eyrolles Baltazar Moreira, nome marcante da vida e cultura portuguesas, veio cumprir um longo exílio no Brasil. Através da vida da escritora passa também, necessariamente, a vida de uma época: o espaço humano, existencial, cultural e geográfico do qual Maria Archer é, para este trabalho, o centro.

Em Portugal a escrita de Maria Archer tem pouca visibilidade, mesmo a família não se preocupou, na época, em preservar a "memória" da autora. Tal constatação é surpreendente, sobretudo após tomarmos conhecimento da variedade e do grande número de livros e artigos escritos, além de uma série de conferências proferidas por esta autora. É farto o repertório de sua produção literária laborada entre 1935 e 1963. Os seus livros atualmente, exceto Ela é apenas mulher, reeditado em 2001, e Nada lhe será perdoado, reeditado em 2006, só pudemos encontrar nos alfarrabistas de Portugal. 
Assim é o caso para se refletir por que essa autora e as suas obras de inegável qualidade foram apagadas na memória de um tempo crivado de silêncio e relegadas ao mais completo esquecimento.

Partimos de um diversificado painel de pontos de interesses, aparentemente divergentes, no conjunto da produção literária da autora, cujas obras transcendem as fronteiras nacionais e étnicas, África, Brasil e Portugal, pudemos encontrar um farto repertório temático à disposição dos leitores, consubstanciado na maior riqueza de gêneros, desde livros infantis, novelas, romances, ensaios, crônicas, artigos, relatos de viagens, até teatro e traduções. Entre a ética da organização do universo sensível e a estética que traduz a vinculação da sua visão de mundo, a produção criativa da autora pode ser vista também como um fator de aproximação cultural nas relações ibero-afro-brasileira.

Há, contudo, um período enigmático em sua vida: o período em que a escritora veio em exílio para o Brasil, nos anos de Salazar e, essa é uma das razões que nos inclinam a nos deter também no "corpus" estabelecido para este trabalho.

Uma vez no Brasil, Maria Archer pareceu inconformada com o modelo cultural que encerrava o padrão da feminilidade previsto para a portuguesa na época do Estado Novo, padrão este que apoiava na teoria de que a dependência e a subserviência são inerentes à condição feminina, escreveu e publicou obras voltadas para a divulgação da cultura dos países em que viveu. Mais ainda, produziu artigos em jornais, sementes de contestação ao domínio salazarista em Portugal, discursos, crônicas e palestras radiofônicas.

Em sua prolongada escala em terras brasileiras Maria Archer realizou, pelo intrincado território da escrita para jornais, uma conexão entre o Índico e o Atlântico interligando-os pelo horizonte da literatura. Ao adentrar no território do gênero periodístico laborado por Maria Archer no exílio e publicado durante a permanência no Brasil, tivemos em vista a classificação e descrição analítica de sua produção criativa para a imprensa. Tal procedimento conduziu-nos à identificação das suas contribuições à imprensa local, bem como os seus conteúdos considerados essenciais e também os subsidiários.

Que tipo de imprensa faziam as mulheres naquele tempo? Pensar o jornalismo de Maria Archer pode sugerir-nos a busca de elementos em que se inscrevem opiniões, pontos de vista sobre o papel da mulher jornalista 
e os modos como se desenvolvem, em seu tempo, as atividades de imprensa periódica.

A idéia de uma condição feminina, naquele momento, permanecia forte e delineava nas colunas as temáticas comuns às mulheres. $\mathrm{O}$ binarismo dos gêneros era herança dos discursos científico e jurídico construídos no século XIX, que desenvolveram a noção de posições e papéis definidos pela condição de gênero.

Várias foram as escritoras em que a atividade literária corria paralela à atuação jornalística. Clarice Lispector ${ }^{1}$ começou a trabalhar como jornalista desde 1940 na Agência Nacional e publicou as primeiras reportagens e entrevistas na revista Vamos Ler! e no jornal A Noite.

Outra escritora que também se articulou nesse mundo diferente da escrita, foi Adalgisa Nery². Entre 1954 e 1966, a escritora passou a opinar como colunista do jornal carioca A Última Hora sobre inúmeras questões referentes à política e à economia nacionais.

A atuação feminina nos jornais tem no exercício jornalístico efetivo de Maria Archer um exemplo modelar. Em suas contribuições para a imprensa no Brasil, dedicou-se com intensidade à produção de crônicas para o Suplemento Feminino de OESP e não só, soube aproveitar convenientemente o espaço aberto ao debate, à informação, e na criação de um público leitor feminino, quer brasileiro, quer português, ao colocarse como mais um esforço no sentido de reconhecer e dar visibilidade à diversidade cultural brasileira geradas a partir das relações África/Europa, no século XX, além de despertar o prazer no hábito de ler quotidianamente.

Ao levantarmos dados biográficos da escritora, fatos de sua vida ainda não conhecidos e razões do seu exílio para o Brasil, cujo percurso, teve em seus primeiros passos a intenção de catalogação de toda contribuição da autora à imprensa brasileira, levou-nos conseqüentemente a um inventário de sua atuação junto ao núcleo de exilados portugueses.

A fim de dimensionar a contribuição de Maria Archer para a imprensa brasileira, situando o seu trabalho de autoria feminina nos tempos do

${ }^{1}$ LISPECTOR, Clarice. Entrevistas. (Organização de Claire Willians, notas bibliográficas de Tereza Montero). Rio de Janeiro: Rocco, 2007.

${ }^{2}$ CANDELORO. Isabela. Entre a Literatura e o jornalismo. A Trajetória da escritora Adalgisa Nery. XI Seminário Nacional Mulhr e Literatura. II Seminário Internacional Mulher e Literatura. ANPOLL. 2005, p. 1016-1027. 
exílio, encontramos trabalhos nas seguintes publicações periódicas: A Gazeta, O Estado de São Paulo e Portugal Democrático.

Concentrar-nos-emos na atividade jornalística da escritora, colaboradora regular da imprensa periódica do Brasil no período de 1955 a 1963 . As crônicas abrangem parte dos anos mais conturbados do regime salazarista: o "corpus" significativo foi endereçado ao jornal O Estado de São Paulo, de 1955 a 1957, contudo, neste trabalho nos voltaremos para o jornal de resistência ao regime salazarista no Brasil, o Portugal Democrático, cujas contribuições se deram de 1955 a 1963.

O percurso da escritora pelo gênero periodístico tem o seu ponto de partida no jornal A Gazeta. Nessa publicação, Maria Archer ao contatar que, em meados do século passado, a circulação literária entre Brasil, Portugal e África, continente que tanto mexeu com a imaginação de viajantes e aventureiros, era praticamente inexistente, traz para a ordem do dia uma reflexão sobre o tema. É, portanto, nas colunas do jornal A Gazeta, que o tema ganha a visibilidade, sob a ótica de uma estreante no gênero em terras brasileiras, ao chamar a atenção para a incipiência da circulação literária entre os países que tem o português como língua de comunicação. $\mathrm{O}$ ensaio, cujo conteúdo postula a defesa da intensificação do intercâmbio literário e cultural faculta, entre outras razões, para as barreiras alfandegárias a responsabilidade pela desfasagem no intercâmbio entre os países que se comunicam através da língua portuguesa.

Isto nos dá uma medida de que forma a autora, a partir do exílio, se adapta à realidade cultural portuguesa e brasileira. É, portanto, sob o olhar e a memória da crônica jornalística da escritora que importa procurar os conteúdos orientadores sobre os quais se deu o encontro do olhar estético na captação da "alma de um povo".

Além de dezenas de crônicas de sensível eficácia literária, por conformarem uma agradável aproximação entre a literatura e o jornalismo, escreveu e publicou no jornal O Estado de São Paulo artigos e ensaios voltados para a divulgação da cultura dos países em que viveu e que mantêm o português como língua de comunicação.

Desta outra margem do Atlântico, Maria Archer, na intenção de manifestar o seu descontentamento diante de posições, atitudes e posturas políticas que julgava incorretas, nas duas décadas que aqui viveu produziu artigos que contribuíram vivamente para a composição do movimento de resistência ao regime conservador e autoritário vigente em Portugal. 
Nasce dessa iniciativa conjunta com vários exilados portugueses: Portugal Democrático (1955-1974), que pretendia divulgar a situação que se vivia em Portugal e seria a concretização da aspiração de se constituir como grupo de anti-salazaristas a partir do exílio. Na publicação periódica Portugal Democrático, portanto, foi além, fez circular vários artigos, sementes de contestação ao domínio salazarista em Portugal.

A década de 50 registra o maior fluxo dos auto-denominados "imigrantes políticos", que irão compor a resistência anti-salazarista na cidade de São Paulo, em particular no Portugal Democrático. Em seu ensaio "Reflexões sobre o exílio" (2003), Edward Said ${ }^{3}$, ele próprio representante da situação de diáspora vivida por muitas pessoas no século XX, afirma que este século é "com efeito, a era do refugiado, da pessoa deslocada, da imigração em massa”. Aqui chegados, os imigrantes exilados darão conta da presença portuguesa no Brasil.

Depois de se sentirem no centro dos acontecimentos em Portugal, em uma conjuntura de repressão maiúscula à liberdade de expressão do pensamento, o exílio foi, para as gerações de 1950 a 1970, a ruptura com uma realidade e o desenraizamento do universo de referências que dera sentido à luta contra o regime de Salazar. A intensa movimentação cultural e as solicitações a que a escritora atendeu na capital paulistana deram mostras da acolhida com que fora distinguida, bem assim da competência da mulher incomum que chegou a transitar com grande facilidade pelos meios intelectuais e nos mais diversos domínios do saber, tais como a política, a cultura, a geografia, a história, a etnografia, a língua estrangeira.

Exemplos dessa atividade são os vários eventos em que Maria Archer foi convidada a se pronunciar. Mediante notório desempenho nas letras, a escritora recebeu em 04 de maio de 1957, na Livraria das Bandeiras, expressiva homenagem, por ocasião do lançamento do seu livro Terras Onde se Fala Português (1957). O jornal A Gazeta daquela data registra a presença de personalidades de destaque dos meios intelectuais.

Teve ainda a autora ativa participação junto a AESP - Associação dos Estudantes Secundaristas Paulistanos, a convite do presidente Valdo Domingos.

${ }^{3}$ SAID, Edward. Reflexões Sobre o Exílio e outros Ensaios. São Paulo: Cia. das Letras, 2003, p. 47. 
As corajosas aparições públicas de Maria Archer logo despertaram a atenção do Departamento da Ordem Política e Social - DEOPS. A exemplo da reunião do dia $1^{\circ}$ de junho de 1957, que teve lugar no Salão Nobre da Associação dos Funcionários Públicos do Estado de São Paulo, o DEOPS deu o seu testemunho contundente acerca da postura coercitiva aos intelectuais por parte do governo salazarista, e referiu-se à invasão da PIDE em sua casa e do confisco dos originais de seu livro ainda por publicar.

Sua presença também se fez notar, conforme os relatórios de "observação preventiva" do DEOPS, no Ato de Solidariedade ao povo cubano, promovido pela União Estadual dos Estudantes, em 24 de janeiro de 1959, onde contou com a participação do Capitão Sarmento Pimentel. Em seu pronunciamento para mais de 1.500 pessoas, Maria Archer iniciou dizendo não estar acostumada a falar de improviso, já que "em Portugal esse costume não pode ser desenvolvido, pois lá temos que escrever tudo o que se vai dizer e submeter à aprovação política do Salazar”, e prossegue:

Heróis anônimos tombam dia após dia, nos porões das cadeias políticas de Salazar, enquanto uma centena de fantoches do governo vive no luxo e no conforto. A colônia portuguesa que se encontra no Brasil, talvez por ser formada na sua maior parte de indivíduos apolíticos, que para cá se dirigem e tenho a impressão que aqui se influenciam pela máquina de propaganda orientada pelo governo português, começa ultimamente a tomar consciência e felizmente, da real situação, o mesmo não se deu quando há dois ou três anos passados para aqui se dirigiu o caixeiro viajante da ditadura general Craveiro Lopes.

A experiência compartilhada entre os mundos em que viveu levou a escritora e jornalista ao encontro de uma maneira de pensar que tendia a desconstruir os paradigmas do conhecimento ocidental, num mundo crescente marcado pela visão anti-colonialista. A crítica tem apontado essa condição de uma forma particular de exílio vivida por muitos intelectuais contemporâneos geradora de um pensamento que se esforça por articular mundos e universos culturais diferentes.

Nesse período muitas foram as produções criativas que construíram a imagem do continente africano no Brasil, numa circulação de saberes e num "imaginário mais amplo, mestiço, oriundo de nossa formação 


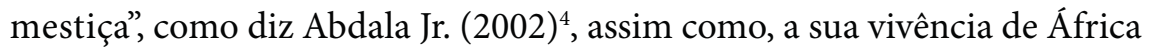
será transformada em objeto das experiências da viagem. Aliados a outros escritos, elaborados face à resistência ao regime de Salazar, Maria Acher, do seu observatório social, lança mão da diversidade étnica e cultural, importante para a nossa constituição de povo, de raça e de processos ideológicos. Desta forma, as narrativas de viagem, e a imprensa, vão exercer importante papel social na construção dos indicadores de práticas culturais e ideológicas. Registros que prenunciam como o século XX recorta o mundo e como as imagens escritas pelo olhar da escritora, se mesclam

Nas duas décadas que aqui viveu, a jornalista lusitana produziu artigos que contribuíram vivamente para a composição do movimento de resistência ao regime conservador e autoritário vigente em Portugal. Nasce dessa iniciativa conjunta com vários intelectuais portugueses exilados, o órgão de imprensa: Portugal Democrático, que pretendia divulgar a situação que se vivia em Portugal e seria a concretização da aspiração de se constituir um grupo de anti-salazaristas a partir do exílio.

O Jornal Portugal Democrático veiculava no primeiro sábado de cada mês; a sua primeira edição saiu em 07 de julho de 1956. Em torno desse jornal havia pessoas de todas as tendências: direita e esquerda, socialistas, comunistas e liberais.

Distanciando-se dos órgãos de propaganda oficial do governo português, informou aos seus leitores, além disso, que o seu propósito era a abertura para toda e qualquer colaboração que visasse servir o "Portugal Democrático" com verdade e independência. Não dispunha de qualquer subsídio. Sua vida passava a depender dos portugueses que, apesar de emigrados, desejam que em sua pátria vigore um regime verdadeiramente democrático conforme o trecho em destaque prossegue expondo a finalidade:

(...) "servir o "Portugal Democrático" com verdade e independência; mostrar aos portugueses que se interessam por Portugal a real situação do país, destacando a cultura portuguesa; mudar a imagem do país, vencer as barreiras da censura, da falta de dinheiro e de apoio, estamos voltados para o futuro, conscientes das realidades do presente e orgulhosos das grandezas do passado.

\footnotetext{
${ }^{4}$ ABDALA JR., Benjamin. Fronteiras Múltiplas, Identidades Plurais. Um Ensaio sobre a Mestiçagem e Hibridismo Cultural. São Paulo. Editora Senac, 2002.
} 
O jornal foi por excelência um espaço da participação masculina, contudo, observou-se a presença de quatro mulheres: Maria Archer, Maria Irolinda, Manuela Gouveia Antunes e Maria Antonia Fiadeiro. Em meio à hegemonia masculina que marcou a produção de conhecimentos e a formação de opinião pública no periodismo de resistência no Portugal Democrático, a participação de Maria Archer, com textos, se verificou a partir da $3^{\text {a }}$ edição quando lançou o seu artigo de estréia: A Censura à Imprensa e ao livro. A.l (4), 6 de Out. 1956, p. 5 e 6 . Artigo em que denunciou o regime repressivo de Salazar, a censura ao ato de pensar e a apreensão dos manuscritos tomados no julgamento no Tribunal Militar em Lisboa, do capitão Norton de Matos que mais tarde se converteria na obra Os Últimos Dias do Fascismo Português um dos seus livros publicados no Brasil (1959).

A autora presenciou o asfixiamento gradativo do seu país de origem com a prolongada vigência do regime salazarista e, ao evidenciar sua experiência ante a opressão vigente em Portugal e expressar de forma consistente a opinião marcadamente oposicionista, Maria Archer habilitou-se, por assim dizer, a inaugurar a participação da mulher no movimento de resistência. A atestá-lo, a introdução de textos de sua autoria naquele órgão de imprensa, onde o exercício de oposição ao regime salazarista era uma "exclusividade masculina”.A partir de então, torna-se voz ativa circulante nos meios de comunicação impressa e falada, no processo de formação de opinião pública sobre o regime de Salazar entre os portugueses residentes no Brasil da época, assim como no desenvolvimento da literatura de autoria feminina em língua portuguesa.

\section{Referências Bibliográficas}

ABDALA JR., Benjamin. Fronteiras Múltiplas, Identidades Plurais. Um Ensaio sobre a Mestiçagem e Hibridismo Cultural. São Paulo. Editora Senac, 2002.

ARCHER, Maria. Terras onde se fala Português, Rio de Janeiro, Ed. Casa do Estudante do Brasil, 1957.

. Os Últimos Dias do Fascismo Português, S. Paulo, Editora Liberdade e Cultura, 1959.

Brasil, Fronteira da África, São Paulo, Felman-Rêgo, 1963.

Portugal Democrático, Dir. Otávio Martins de Moura "A censura à Imprensa e ao livro." 6 de Out. 1956, p. 5,6.

. "Um Vencido". 12 Jan. 1957, p. 6. 
(conclusão).

. "Carta aberta a sua majestade Britânica Isabel II", p. 1,4,2

. "Eu e A Voz", Abr. 1957 p. 1, 6.

. "Eleição de candidato único", Mai. 1957, p.1, 4.

. "Somoza, Salazar e Ca.", Jul 1959, p. 6.

. "A revolução áurea., Out. 1960, p. 6, 7.

. "Avacalhar e Portugalizar.", Set. 1961, p. 7.

. "Brasil, Fronteira da áfrica., Set. 1963, p. 4.

. "Símbolo e Mito do 5 de Outubro.", Out. 1963, p. 8.

PESSOA, Fernando. "Palavras de Pórtico", In: Introdução à Obra poética. Rio de Janeiro: Aguilar, 1965, p. 16.

RODRIGUES, Miguel Urbano. O Tempo e o Espaço em que Vivi, I - Procurando um caminho. Porto, Campo das Letras, 2002.

. "Portugal Democrático: Um jornal revolucionário". In: O Tempo

e o Espaço em que Vivi, I - Procurando um caminho. Porto, Campo das Letras, 2002, p. 184.

RODRIGUES FILHO. José Maria. Monografia Emigração, Jornalismo, Educação e Luso-brasilidade em "Saibam quantos..." de Fialho de Almeida. Trabalho da Disciplina Relações literárias Brasil/Portugal apresentado na FFLCH - USP, 1997. (digitado).

ROSAS, F. “O Estado Novo 1926-1974”, J. Mattoso (ed.) , História de Portugal, 7, Lisboa, Editorial Estampa, 1992.

SAID, Edward. Reflexões Sobre o Exílio e outros Ensaios. São Paulo: Cia. das Letras, 2003.

SALIS Viktor D. "Os Grandes Princípios Míticos". In: Mitologia Viva. São Paulo, Nova Alexandria, 2003, p. 209 a 229.

SILVA, Douglas Mansur da. A Ética da Resistência: Os Exilados Anti-Salazaristas do "Portugal Democrático" (1956-1974). Dissertação de Mestrado. Orientadora: Profa. Dra. Bela Feldman Bianco. Campinas, Unicamp, 2000.

SODRÉ, Nelson W. História da Imprensa no Brasil. São Paulo, GRAAL, 1997.

Recebido em 25 de novembro de 2007

Aceito em 27 de fevereiro de 2008 